that the public mind is rapidly being enlightened as to the incidence and nature of infectious disease. That whilst it is advisable to increase that light, and direct it to proper efforts, it is quite equally desirable that the foolish panic and cowardly dread of this kind of disease now prevailing should not be fostered and pampered by two fussy legislation. Something must be trusted to education, and the diffusion of the knowledge of sanitary science amongst all classes, the poor especially. The time will come when the public will render intelligent aid to the authorities in these matters; whilst if their ignorant fears be now played upon to a greater extent than necessary, they will take refuge in evasion or opposition to even reasonable measures.

I am, Sir, your obedient servant,

Worcester, March 1st, 1880.
Medical Officer of Health.

\section{"THE CORONER'S FUNCTION."}

\section{To the Editor of THE LANCET.}

SIR,--The scheme propounded in your leading article on the "Coroner's Function," for combining certain Stato duties under the office of the Medical Officer of Health, is one which commends itself as being both practicable and as meeting mary anomalies and deficiencies which now prevail in the varied administrations of the medical world.

I venture to add to your suggestions; and to draw from a similar proposal which I made in 1878 at the North Wales Poor Law Conference (see Report for that year), and in a paper published in the August (1879) number of the "Sanitary Record." Whilst advocating combined sanitary districts, it was proposed also to combine allied offices under the medical officers of health; and it was shown that by this combination sanitary work would be more efficient, and also that the present salaries attached to these various offices would yield a handsome income to an independent officer without further assistance from rates. The offices which it was proposed to combine under the medical officer of health are those of the "certifying factory surgeon," the "superintendent registrar of births and deaths," and that of "coroner." Each of these offices works in a manner in duplicate and anomalously, either with the functions of the Medical Officer of Health or with some other Court of Inquiry. Thus the Public Health Act, 1875, section 91, brings small factories only under the supervision of the medical officer of bealth, leaving the large ones under the certifying factory surgeon. And yet the medical officer of health is required by the Local Government Board General Order of Nor. 11th, 1872 (section iv., paragraphs 10, 14), to inquire into processes of trade, and to report upon appropriate means to prevent injury to health therefrom. Again, the medical officer of health is by the same general order (paragraph 14) called upon to deal statistically with the mortality in his district, his data being gathered from copies of the registers supplied him at the cost of the sanitary authority by the sub-district registrars. The superintendent registrars are not called upon to deal with the information their registers afford, and do but transmit the sub-district returns to the RegistrarGeneral, and, as occasion may require, supply duplicate certificates to such persons as may require them. Obviously by combining these two offices with that of the Medical Officer of Health an administrative and pecuniary economy would be effected.

The Coroner's office, if its utility has not altogether ceased, is certainly in need of reform. At the present time important inquiries conducted in this court are for the most part repeated in either the police courts or by the Board of Trade. And for the less important inquests, a personal inquiry, conducted as by the procurator fiscal in Scotland, would meet every requirement, to which should be added, to complete the designs of the Registration Enactments, a similar inquiry into every uncertified death.

By colleeting together under one administrator the scattered forces which have been called into existence for the protection of life and health, a greater proficiency will pertain to each office. By this means, and in the manner you, Sir, indicate, skilled medico-legal functionaries will fill the offices of the Medical Officer of Health. Ample work and remuneration are at hand from existing sources in limited and workable districts; and the whole should be under the control of a Minister of Health.

I am, Sir, your obedient Servant,

Denbigh, Feb. 25th, 1880.
THE TREATMENT OF ACUTE RHEUMATISM. To the Editor of THE LANCET.

SIR,-DD. Barton's wise remark about " the search for new remedies" is exceedingly well timed, and his brief record of his large experience exceedingly interesting; but his results would acquire a new value if he could only see his way to put them into a statistical form. The obvious answer to Dr. Barton's astonishment at my omission to mention iodide of potassium and opium is, that the scope of my paper was necessarily limited, and did not include either of these drugs.

Dr. Jacob states that "subsequent observers (to Dr. Fuller) have failed to secure by alkalies a like success." No doubt many have so failed, and I have distinctly said so but, on the other hand, many eminent physicians have recorded most gratifying successes. Have the failures not been due in some measure to the lack of that care and assiduity which characterised Dr. Fuller's practice? Many surgeons fail to obtain the same brilliant results with the antiseptic treatment of wounds as my esteemed teacher, Professor Lister. But do they follow his practice rigorously in all its details? The percentage of cardiac complications in all the groups of cases of acute rheumatism treated by the salicylate of soda, to which Dr. Jacob refers, is greater than in Dr. Fuller's practice, with the single exception of the German group, which is less than a fourth of the number of Dr. Fuller's cases, and so may contain fallacies from which a large group is more likely to be exempt.

The error into which $I$ have fallen in reading Dr. Pollock's "Notes on Rheumatism" is one which I greatly regret, but which I cannot regard as unnatural. I read his excellent brochure without prejudice of any kind, and I came to the only conclusion regarding his therapeutic leanings that seemed possible-namely, that he is a strong partisan of the new method of treatment. This being so, I examined his appendix in the hope of finding an exceptionally brilliant record of experience. I found, instead, "three fatal cases in a total of sixteen." I am always glad to hear of a low rate of mortality, and I need hardly express my pleasure in finding that the total was between sixty and seventy. Still, even this proportion of fatal cases is too high, in my opinion, to entitle anyone to speak of salicylate of soda in the unqualified terms employed by Dr. Pollock.

Dr. Whipham's explanation is gratifying; but he must remember that the mention of "no cardiac lesion" was made in the note of October 25th, while the cardiac affection to which I referred is spoken of in the notes of October $26 \mathrm{th}$ and 27 th and November 4 th. However, even admitting that $I$ was led astray by the notes of his case, the question at issue is not seriously affected.

I had three objects in view in writing my paper :-1st. To show that the virtues of the new method have been vastly overrated, and its dangers greatly underrated. 2nd. To prove that the published results of other methods should not be despised. 3rd. To draw the attention of the profession to the importance of distinguishing clearly between continued and relapsing cases. It stands to reason that if a group contains a large proportion of relapsing cases, the average duration of rheumatic symptoms and the average residence in hospital must be greater than in a group which contains a small proportion of such cases. This consideration should be kept in mind in estimating the value of the statistics of St. George's Hospital and the Dundee Royal Infirmary.

Dundee, Feb. 28th, 1880.

I am, Sir, your obedient servant,

THE STAMPING OUT OF RINGWORM.

\section{To the Editor of THE LANCET.}

SIR,-The profession is much indebted to Dr. Alder Smith for his valuable contribution to the subject of the treatment of ringworm, which has appeared in your columns lately. We have been taught some useful facts as to remedies, especially the mode of applying them, and the extent to which they may be pushed.

Even with the supervised and vigorous treatment which Dr. Smith's opportunities permit, ringworm, excepting in a few recent cases, is shown to take months to cure, while 
some cases may be said to be incurable. What degree of such vigorous treatment or supervision do the bulk of hospital patients receive? It is well known that children with ringworm are not, as a rule, admitted to hospitals, but treated in the out-patient department. As a consequence the cases drag on month after month, until, tircd of one hospital, the parents try another, or possibly go the round. Probably long before this the case has drifted into "the diffused form," in which the ordinary appearances of ringworm are absent; the child is considered to be cured and sent to school. In this way ringworm is spread, and if the matter were inquired into, it is not unlikely that many schools, and especially school-board schools, would be found to be hot-beds of ringworm.

The point urged, then, is that our present hospital system of treatment of ringworm is utterly unsatisfactory, and, in many instances, mere waste of time and drugs. The remedy which naturally suggests itself is systemised intelligent aid from nurses and attendants at out-patient departments, so that methods might be properly carried out. (The parents of children rarely bave the time, inclination, or ability to treat them.) But much more good might be done in the direction of stamping out the disease by some special system of medical supervision of school-board schools.

\section{I remain, Sir, yours, \&c.}

AlfRed SANGSTER, M.B.

Feb. 12th, 1880. Physician in Charge of Skin Department, Charing-cross Hospital.

\section{IS INSANITY CAUSED BY DRINK?}

\section{To the Editor of THE LANCET.}

SIR,-The question raised by Dr. Mortimer-Granville in his letter appearing in THE LANCET of the 21st ult. is, I think, by no means an unimportant one.

I have now been specially engaged in the treatment of mental affections for a period of some thirty-six years. In the course of my practice $I$ have met with many cases of insanity in which there was the propensity to take stimulants in excess; but in every case in which $I$ had the means of obtaining reliable information as to the history of the patient I have been able to trace the mental disease as existing before the intemperance.

I am, Sir, yours faithfully, JOSEPH SEATON.

Halliford House, Sunbury, March 8th, 1880.

\section{EXTENSION OF THE FUNCTIONS OF MEDICAL OFFICERS OF HEALTH. \\ To the Editor of THE LANCET.}

SrR,-I have read with pleasure your able leading article of last Saturday on the various subjects about to occupy the consideration of the present Parliament, which more or less affect the medical profession - to wit, the Coroner's Bill and the Lunacy Laws; and while agreeing with you that the duties under these laws devolving upon a public officer should be put upon the medical officers of health, $I$ fail to see how these gentlemen as now appointed can, satisfactorily to themselves, perform them.

As you state there will be, in all likelihood, a considerable alteration in the laws, and if the medical officers of health are to be called upon to undertake more onerous duties they must of necessity be entirely relieved from private practice; and to accomplish this it will be necessary in many cases to enlarge the area of districts, in order that an adequate salary can be given.

Again, besides sanitary duties and those proposed under the Coroner's Bill and the Lunacy Laws, there are others that might, with all propriety, be handed over to the medical officer of health-namely, those of inspector of retreats under the Habitual Drunkards Act, and of certifying factory surgeon.

To enable them to perform the duties mentioned above, I can see no other course that can be followed than for the Government to appoint the medical officers of health, and pay them such salaries as they can comfortably live upon, and then Government might repay itself in seven years, by making a levy upon the various authorities to whom the medical officer of health lent his aid.

The corps of medical officers of health ought to be under a chief who would have power to regulate appointments and remove officers from one station to another, as it does in the other branches of the public service, and it might have various grades or ranks, with corresponding rates of pay, according to service and ability. No one should be allowed to remain in this service who has attained the age of sixty-five years.

Feeling certain that it is only by such an arrangement that the proposals mentioned in your last impression can be carried out, and having been a medical officer of health ever since the Public Health Act came in force, I am induced to send you this communication.

I enclose my card, and remain yours faithfully, Feb. 24th, 1880. Public OFficer,

\section{EDINBURGH.}

(From aur own Correspondent.)

DURING the past fortnight Dr. Thomas Keith has per. formed three ovariotomies in the Royal Infirmary, all being of special interest. One was a semi-solid tumour, which had existed for two years in a patient who had been thrice pregnant during that period. There were no adhesions. A second was a case of burst cyst. The patient was in a poor state of health; she had been in hospital for some time, suffering from pleurisy and chest disease, when the sudden rupture of the cyst called for operative interference. The third case was one of a girl about fourteen years of age, who had never yet menstruated. There were some anterior ad. hesions: Remarking on this case, Dr. Keith stated that he had seen an ovarian tumour in a seven months foetus; that such growths might be met with at any period of life, and that he had himself operated on patients where age varied from nimeteen to over seventy years. The burst cystwas removed in the ward and the other two cases in the large theatre. The usual antiseptic precautions were adopted. It is much to be regretted that the light in the theatre is $\$ 0$ fanlty that Dr. Keith fears he must be compelled to cease operating there until some new mode of illumination be devised.

Among many other major operations, there have been two lateral lithotomies. In one case a large discoid stone was removed by Professor Spence, and in the other a small uric acid calculus, by Mr. Chiene, from the bladder of a man whose general state of health contra-indicated crushing. In both cases the rectangular staff was employed, the incision, however, being made in the ordinary fashion. The patients are doing well.

In a discussion which took place at the Medical and Chirurgical Society on the reading of a paper on "Death during the Administration of Chloroform," it appeared to be the general opinion of the surgeons present that this anxsthetic was, on the whole, the best. That in cases of danger it was necessary to see that the glottis was open, and to begin ar. tificial respiration (Silvester's) at once. Special stress riss laid upon the point that the pulling forward of the tongue forcibly did not open the glottis in some cases, and Mr. Bell directed attention to a case of his own, in which he had overcome this difficulty by pushing his finger down to and opening the larynx. Professor Annandale spoke of a deatl which lappened at the conclusion of an operation for hernia, and in which, as revealed by post. mortem examination, some vomited food had passed into the bronchi and choked the patient. Dr. Foulis preferred ether to chloroform and Howard's mode of artificial respiration to Silvester's. Dr. Duncan remarked that in performing artificial respiration the feet of the patient should be secured, as this prevented him from being pulled off the table during the manipulative procedure. Dr. Watson drew attention to the title of the paper, and stated that many deaths took phoce during the administration of chloroform, not from it. He had seen a case of death from epilepsy while chlorotorm was being administered.

Professor Fraser's lecture on "Alcohol, its place and func" tion," delivered at the request of the University and Nerf College Temperance Society, is about to be published. Dr. Fraser expressed himself as favourable to the moderate use of stimulants, and had more hope in the advance of education and knowledge as a means of checking the abuse of alcohol than in abstinence. 